\title{
Enhanced high cycle fatigue resistance of Ti-17 titanium alloy after multiple laser peening without coating
}

\author{
Yang Jiao ${ }^{1}$ (D) $\cdot$ Weifeng $\mathrm{He}^{2} \cdot$ Xiaojun Shen $^{3}$
}

Received: 4 March 2019 / Accepted: 7 June 2019 / Published online: 25 June 2019

(C) The Author(s) 2019

\begin{abstract}
High cycle fatigue failure of titanium alloy components on the aircraft is a serious problem that affects the flight safety. The low energy laser peening without coating (LPwC) has been demonstrated for the improved fatigue resistance of metallic materials via the introduction of compressive residual stress and microstructure modifications. Therefore, in the present study, LPwC with different impacts were conducted on the Ti-17 titanium alloy using the Mianna-Q laser with the wavelength of $532 \mathrm{~nm}$ and energy of $85 \mathrm{~mJ}$. The surface and depth-wise residual stress and micro-hardness distributions were presented on the samples with and without LPwC treatment. High amplitude compressive residual stress was introduced, and the hardness was significantly improved. The microstructures of the Ti-17 samples after LPwC was characterized using the X-ray diffraction (XRD), scanning electron microscope (SEM) and transmission electron microscope (TEM). Furthermore, high cycle fatigue performance of the ascast, LPwCed sample with 1 impact and LPwCed sample with 3 impacts was evaluated via the tension-compression fatigue test. The fatigue strength of the LPwCed specimen was increased from 390 to $475.4 \mathrm{MPa}$ (1 impact) and $490.3 \mathrm{MPa}$ (3 impacts). Then, the fracture morphology of all the specimens were characterized by the SEM. Finally, the strengthening mechanism was discussed based on the microstructural evolution and residual stress distribution. It was concluded that the enhancement of high cycle fatigue strength was attributed to the combined effects of LPwC-induced compressive residual stress and high-density dislocations.
\end{abstract}

Keywords Laser peening without coating $\cdot$ High cycle fatigue $\cdot$ Ti-17 titanium alloy $\cdot$ Residual stress $\cdot$ Microstructure

\section{Introduction}

Titanium alloys, like Ti-6Al-4V and Ti-17, have the advantages of light weight, good toughness, high strength-to-weight ratio and excellent corrosion resistance, which makes it to be widely used in the aerospace and marine industries [1-3]. More specifically, with these unique features, these alloys are widely used for the fabrication of the compressor and fan blisks that were called "cold" components in aeroengines [4]. However, these components may encounter very complex and

Yang Jiao

JiaoY2@cardiff.ac.uk

1 Cardiff School of Engineering, Cardiff University, Cardiff CF24 3AA, UK

2 Institute of Aeronautics Engine, School of Mechanical Engineering, Xi'an Jiaotong University, Xi'an 710049, Shaanxi, China

3 School of Mechanical, Aerospace and Automotive Engineering, Coventry University, Coventry CV1 5FB, UK severe service conditions during operation, like high-frequency vibration and foreign object damage during landing and takeoff, which may cause micro-cracks or dents on the surface [5]. Moreover, titanium alloys are quite sensitive to surface cracks and stress concentration which can lead to cracking and finally the fracture failure of the engine components [6]. It is well known that cracks always initiate from the surface $[7,8]$, so it is of great importance to improve the surface properties of these components. Hence, a number of surface treatments, like shot peening $[9,10]$, surface mechanical attrition treatment [11] and laser shock peening [12], have been applied on the titanium alloy components. However, each one has its own advantages and drawbacks, for example, shot peening has low cost but may lead to the damage of the components surface, the major disadvantage of laser shock peening is that it requires an elaborated laser system with high power and also needs to replace the protective coating after finishing one impact, which may affect the machining efficiency and costs.

Laser peening without coating ( $\mathrm{LPwC}$ ), which was developed in 1995 by Mukai et al. [13] based on the conventional laser shock peening (LSP), is a new kind of surface treatment 
that uses lower energy laser ( $\mathrm{mJ}$ range), smaller laser spots ( $\mu \mathrm{m}$ range), shorter pulse duration (several $\mathrm{ns}$ ) and no protective coatings to effectively enhance the mechanical properties of metallic components via the laser-induced shock wave, for example, in the nuclear power plants [13-15]. LSP and LPwC both take advantage of the laser-induced shock wave to introduce high-strain rate plastic deformation on the surface of the metallic material to improve its mechanical performance. Compared with the conventional laser shock peening, the attractiveness of $\mathrm{LPwC}$ is that it can be done without any surface preparation or protective coating on the target material [15]. Thus, it is not surprising that a number of researchers have used the LPwC on the metallic materials, such as stainless steel [15-19], aluminium alloys [20-24] and titanium alloys [25-28] in the past 20 years. For example, Y. Sano et al. [15] applied the laser peening without protective coating on the 304 and 316L stainless steel. It was demonstrated that laser peening without protective coating can completely prevent the stress corrosion cracking initiation of 304 stainless and also can enhance the fatigue strength of 316L stainless steel. D. Karthik and S. Swaroop [16] investigated the effect of LPwC on the microstructures of AISI 321 steel and the thermal stability of the LPwC-induced compressive residual stress and hardness. They showed that $\mathrm{LPwC}$ can induce martensitic phase transformation on the surface layer of the target material, but the grain is not refined. The $\mathrm{LPwC}$-induced residual stress was released after the heat treatment but micro-hardness almost keeps the same. In addition, the wettability characteristics and pitting corrosion resistance of AISI304 stainless steel after laser shock peening without coating were studied by S. Prabhakaran et al. [19] who found that the hydrophilic untreated surface was converted into the hydrophobic surface as well as the increased pitting corrosion resistance after LPwC. Y. Sano et al. [20] also applied the LPwC to improve the high cycle fatigue strength of friction stir-welded aluminium alloy specimens and concluded that the laser-induced compressive residual stress, together with the increased hardness, plays an important role in recovering the fatigue strength.

The application of $\mathrm{LPwC}$ on the titanium alloys, which is the specific focus of the study reported here, has also been investigated by a few researchers. A. Umapathi and S. Swaroop [25] investigated the residual stress distribution and the accompanying deformation mechanisms on the $\mathrm{Ti}-25 \mathrm{Cu}$ alloy after $\mathrm{LPwC}$ with different overlap rates. Later the 532$\mathrm{nm}$ Nd:YAG laser was used to process the TC6 titanium alloy with different laser power densities and peening times [26]. It was found that the micro-hardness can be increased and also decreased by $\mathrm{LPwC}$, which is determined by the laser parameters. The high cycle fatigue (HCF) performance of three kinds of titanium alloys, namely $\alpha$-Ti alloy Ti-2.5 $\mathrm{Cu},(\alpha+$ $\beta)$-Ti alloy TIMETAL Ti-54M and metastable $\beta$-Ti alloy TIMETAL LCB (in the following LCB), after LPwC were investigated by E. Maawad and Y. Sano et al. [27]. The enhancement was compared with those treated by shot peening and ball-burnishing process. It was reported that the $\mathrm{LPwC}$ can markedly improve the HCF fatigue performance of Ti2.5 Cu and $\mathrm{LCB}$, but the $\mathrm{LPwC}$ deteriorated the HCF performance of Ti-54M. Moreover, in the same research group, it was found that the low- and high-cycle fatigue strength of Ti6Al-4V with LPwC treatment at elevated temperatures can be significantly improved [28]. Under elevated temperatures, the compressive residual stress was essentially relaxed but the laser-induced dense dislocation tangles played the beneficial role in the fatigue strength of Ti-6Al-4V. Although many previous studies have explored the fatigue performance of titanium alloy with and without $\mathrm{LPwC}$, the specific origin of the enhancement mechanism is still not clear and further investigations are required. To the best of author's knowledge, few scientific reports have investigated the high cycle fatigue resistance of Ti-17 dual-phase titanium alloy after laser peening without coating so far. This work here is an attempt to investigate the effects of $\mathrm{LPwC}$ on the high cycle fatigue resistance, residual stress distribution and micro-hardness variation of Ti17 titanium alloy. The microstructures were also characterized, and the strengthening mechanism was discussed.

\section{Experimental}

\subsection{Materials}

The specimens were obtained from a plate of Ti-17 titanium alloy with the thickness of $5 \mathrm{~mm}$. The nominal chemical composition of Ti-17 titanium alloy was Ti-5Al-4Mo-4Cr-2Sn$2 \mathrm{Zr}$ (in wt\%) (Table 1). For the convenience of laser peening and material characterization, squared plate specimens with a dimension of $10 \times 10 \mathrm{~mm}$ were cut from the as-cast (AC) plates using the wire electric discharge machining with the low speed to avoid oxidation. In addition, the fatigue test specimens were cut from the AC plates; then, the thickness was reduced, and the surface scratch and defects were removed. The sketch of the fatigue test specimen, which was manufactured according to the standard of the Aeronautical Department Standard of China (HB 5287-96 axial loading fatigue test of metal materials), is shown in Fig. 1. Further, prior to the laser peening, the surface of the specimens was polished on the 800-, 1200- and 2000-grid SiC paper followed by the final polishing with the $1 \mu \mathrm{m}$ diamond gel suspension

Table 1 Chemical compositions of Ti-17 titanium alloy

\begin{tabular}{lllllll}
\hline Element & $\mathrm{Al}$ & $\mathrm{Mo}$ & $\mathrm{Cr}$ & $\mathrm{Sn}$ & $\mathrm{Zr}$ & $\mathrm{Ti}$ \\
\hline $\mathrm{Wt} \%$ & $4.5-5.5$ & $3.5-4.5$ & $3.5-4.5$ & $1.6-2.4$ & $1.6-2.4$ & Bal. \\
\hline
\end{tabular}


Fig. 1 Sketch diagram of the fatigue test specimen (the red dashed region in the central arc park is $\mathrm{LPwC}$ processed area and the blue dashed region is fixed area in the fatigue test). Units: $\mathrm{mm}$

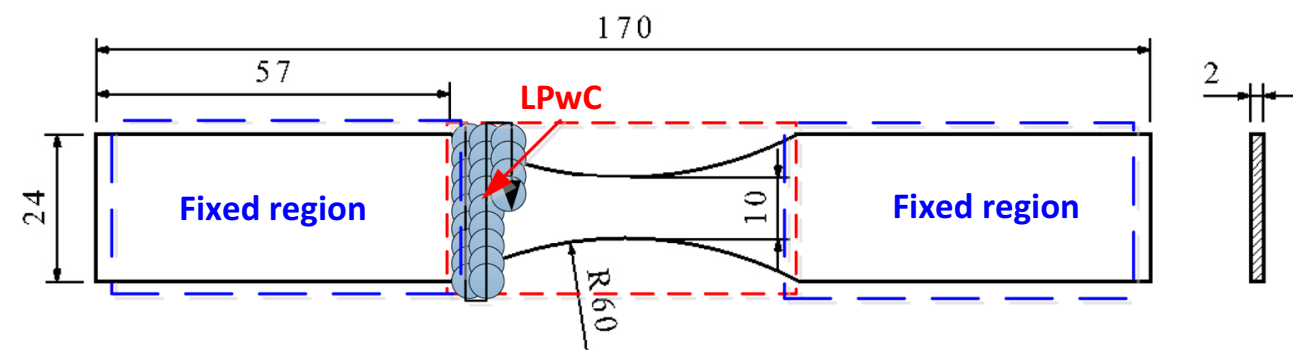

on the top cloth to a mirror-like appearance. For microstructural characterization, the specimens were further cleaned with the acetone to remove the impurities and the small particles from the surface.

The microstructures of the AC specimen were observed under the SEM after being etched in the chemical reagent (90 $\mathrm{ml}$ of $\mathrm{H}_{2} \mathrm{O}, 8 \mathrm{ml}$ of $\mathrm{HNO}_{3}, 2 \mathrm{ml} \mathrm{HF}$ ) for $15 \mathrm{~s}$ at room temperature, as shown in Fig. 2. It indicates that the Ti-17 titanium alloy has a coarse duplex microstructure consisting of $\alpha$ phase surrounded by $\beta$ phase flakes. This unique duplex microstructure allows Ti-17 to exhibit excellent mechanical properties [29].

\subsection{Laser peening without coating (LPwC)}

The laser peening without coating experimental (LPwC) setup is schematically shown in Fig. 3, which is composed of three parts, namely laser control system, X-Y translation platform and Mianna-Q laser. The translation movements in $x$ - and $y$ directions were controlled by two servomotors, operated through a self-developed software. The sample was fixed in a transparent sink and immersed in the water. This water served as a transparent overlap to create the plasma on the sample surface and confine the laser-induced shock wave. When the high-intensity laser directly irradiates the sample, the surface layer starts to ablate immediately. The laser-

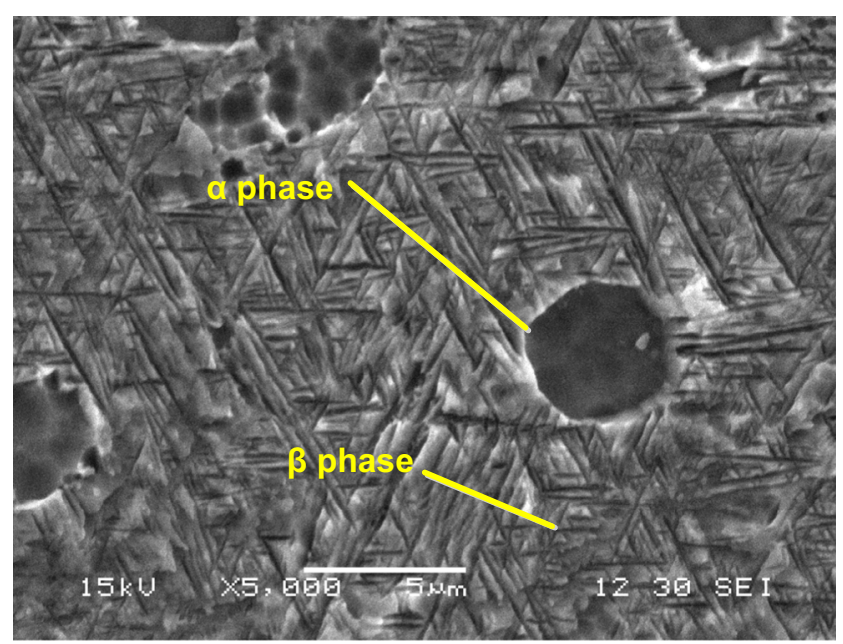

Fig. 2 Morphology and grain size of the as-cast Ti-17 titanium alloy material interaction produces the sudden vaporization of the surface. When the upcoming laser energy is absorbed by the metal vapours, they are transmuted to the plasma plumes. Under the confinement of the water, the rapid expanding plasma plumes will induce the high-pressure shock wave (several GPa) which propagates into the material. With the shock wave, the surface layer of the sample surface experiences the high-strain rate plastic deformation, thus introducing beneficial compressive residual stress and microstructure changes $[17,22]$. Without the protective coatings that are commonly used in the conventional LSP, the direct laser irradiation can cause ablation or even surface damage of the surface. However, low laser energy can minimize the thermal effects and effectively improve the mechanical properties of the target materials. Therefore, in the present study, a low laser energy of $85 \mathrm{~mJ}$ was selected [30].

Experiments were performed with a pulsed Mianna-Q laser system with the wavelength of $532 \mathrm{~nm}$ and a pulse duration of $10 \mathrm{~ns}$ (FWHM). A beam diameter of $400 \mu \mathrm{m}$ was focused on the specimen and multiple pulses of 1, 3 and 5 impacts at the laser energy of $85 \mathrm{~mJ}$ was taken into account. In order to minimize the scattering loss of the laser pulse caused by the ablation products, the water was replaced after finishing the treatment for one sample. As is shown in Fig. 1, a zigzag-type LPwC scan was employed to the samples. The detailed LPwC parameters are shown in Table 2.

\subsection{High cycle fatigue test}

The conventional method, like staircase, for determining fatigue strength at high cycle counts is considered to be time consuming. In the past several decades, numerous accelerated tests for fatigue test have been proposed, among which the "step-loading method" proposed by T. Nicholas [31] and Maxwell [32] is thought to be the standard of reference for the accelerated testing methods, which has been found to be widely used in the US Air Force's project. In this study, the stress ratio is set to be 0.1 and the cycle limit is $10^{6}$. Firstly, the original stress level is set to be $60 \%$ of the expected fatigue limit, which is estimated according to the mechanical properties of the Ti-17 titanium alloys. Further, after each runout of $10^{6}$ cycles, the stress was increased by approximately $10 \%$ until failure occurred at less than $10^{6}$ cycles. And finally, the 


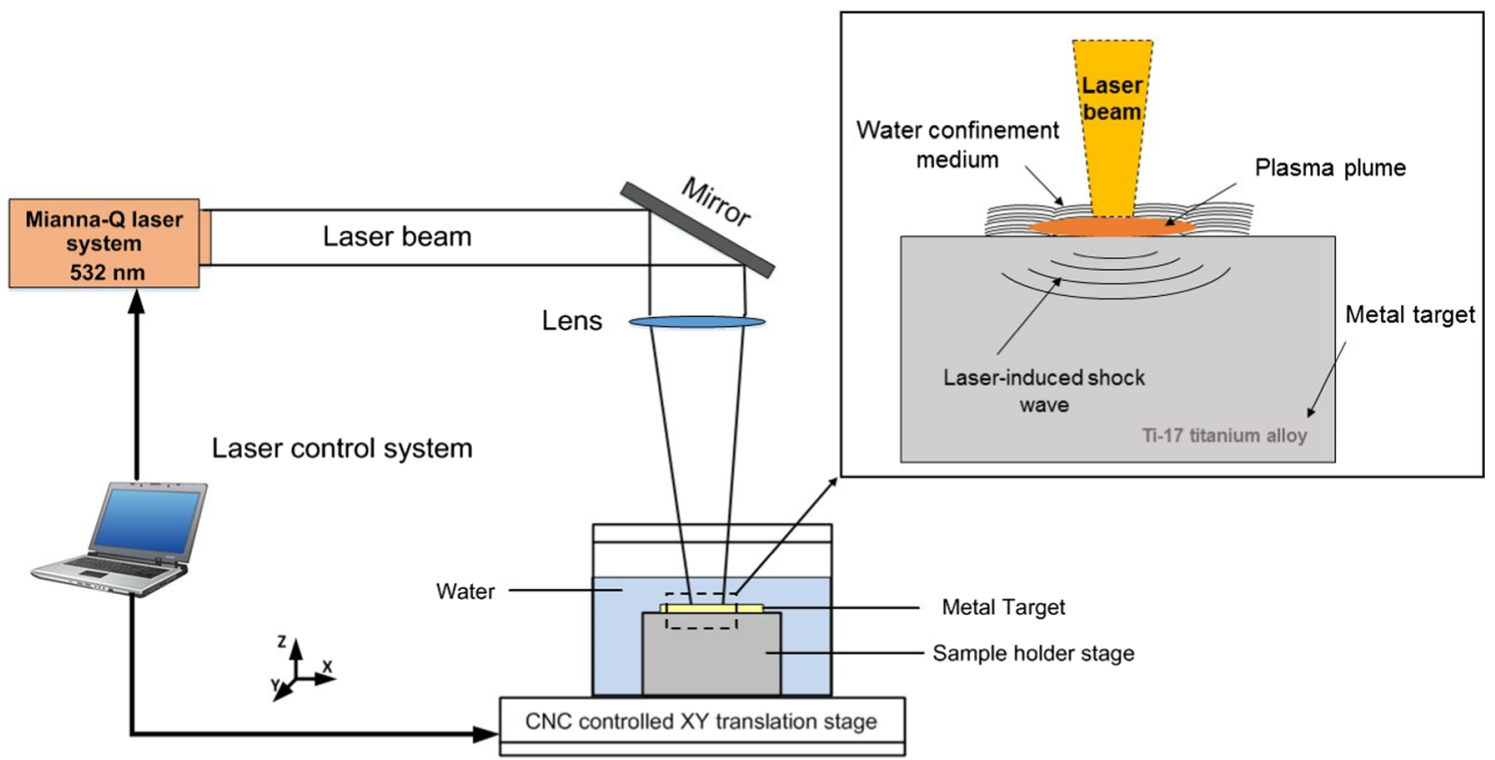

Fig. 3 Schematic diagram of the laser peening without coating process

fatigue limit stress was then determined by assuming a linear damage law between the final loading block and the previous block as described in the following equation:

$\sigma_{e}=\sigma_{0}+\frac{N_{f}}{N_{l}} \times \Delta \sigma$

where $\sigma_{e}$ is the value of maximum fatigue strength corresponding to a life of $10^{6}$ cycles, $\sigma_{0}$ is the stress level of the previous one block of cycles before failure occurred, $\Delta \sigma$ is the step increase, $N_{f}$ are the failure cycles at the stress level of $\left(\Delta \sigma+\sigma_{0}\right)$ and $N_{l}$ is the defined cyclic fatigue life $\left(10^{6}\right.$ in this study). And the step-loading procedure is shown schematically in Fig. 4 for the block of $10^{6}$ cycles.

The tension-compression fatigue test was conducted on the CCQB-100 resonant fatigue testing machine from Qianbang Ltd (Chang Chun, China). All the tests were carried out under sinusoidal waveform with the frequency of $85 \mathrm{~Hz}$ and at the room temperature. After the fatigue test, the fracture surface morphology was observed by JEOL JSM-6360LV scanning electron microscopy (SEM) from JEOL Ltd (Japan).

Table 2 Laser processing parameters for TC17 titanium alloys

\begin{tabular}{ll}
\hline Laser parameter & Value \\
\hline Wavelength $(\mathrm{nm})$ & 532 \\
Pulse energy $(\mathrm{mJ})$ & 85 \\
Pulse duration $(\mathrm{ns})$ & 10 \\
Repetition rate $(\mathrm{Hz})$ & 3 \\
Spot diameter $(\mu \mathrm{m})$ & 400 \\
Overlapping rate $(\%)$ & $60 \%$ \\
Laser impacts & $0 / 1 / 3 / 5$ \\
\hline
\end{tabular}

\subsection{Material characterization}

Residual stress distribution was determined by the X-ray diffraction-based Proto-LXRD stress analyzer using the $\sin ^{2} \psi$ method. The X-ray beam diameter was about $2 \mathrm{~mm}$; the voltage and current of the X-ray source were $30.0 \mathrm{kV}$ and $10.0 \mathrm{~mA}$, respectively. The Ti plane was detected with a $2 \theta$ of $137-145^{\circ}$, with a step width of $0.10^{\circ}$ and $0.5 \mathrm{~s}$ for each step. The electrolytic polishing layer by layer removal method was chosen for the in-depth measurement of the residual stress and micro-hardness with the electropolishing solution which was composed of 10 vol\% perchloric acid and 90 vol\% methanol. The electropolishing was carried out with the PROTOElectropolish system under the voltage of $45 \mathrm{~V}$.

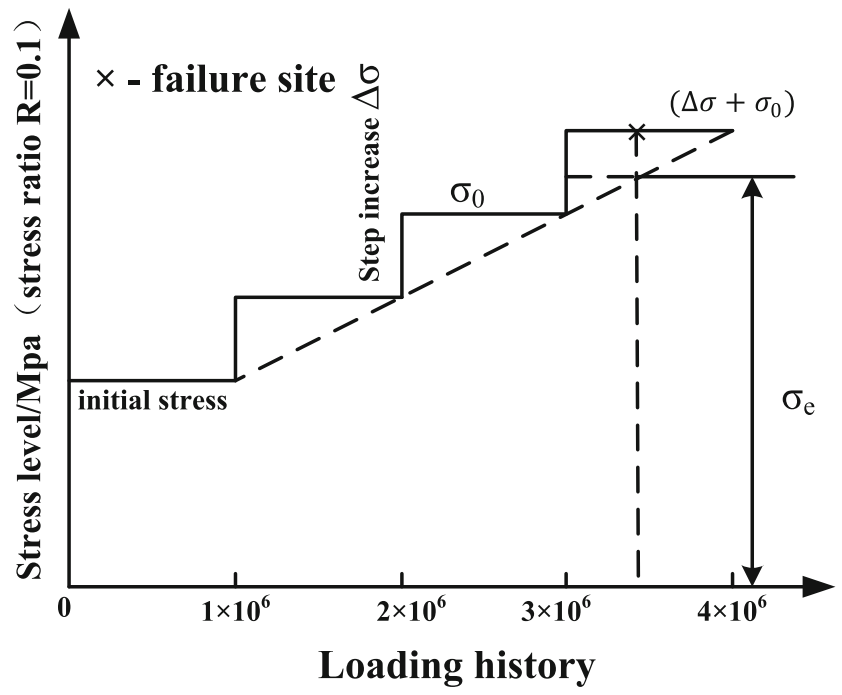

Fig. 4 Schematic diagram of step-loading procedure 
The Vickers hardness profiles on the surface and cross section of the specimens before and after $\mathrm{LPwC}$ were measured using a MVS-1000JMT2 micro-hardness tester with an indentation load of $500 \mathrm{~g}$ and a dwell time of $15 \mathrm{~s}$. In order to ensure the reliability of experimental results, each indentation was measured 5 times and then the average result was determined as the final hardness value.

The phase transformation analysis of Ti-17 titanium alloys was conducted via the Bruker D8 X-ray diffraction equipment using $\mathrm{Cu}-\mathrm{K} \alpha$ radiation (wavelength, $0.15418 \mathrm{~nm}$ ) with a scanning speed of $0.01 \% \mathrm{~s}$ at the generator settings of $40 \mathrm{kV}$ and 35 $\mathrm{mA}$. The data was collected over a $2 \theta$ range of 20 to $80^{\circ}$ and a counting time of $5 \mathrm{~s} / \mathrm{step}$. The microstructures in the surface and the cross section of titanium alloys were observed by the JEOL JSM-6360LV scanning electron microscope (SEM) and the TEM-3010 transmission electron microscope (TEM); the TEM samples were prepared by grinding the substrate to a thickness $<50 \mu \mathrm{m}$ which is achieved by twin-jet thinning with a double-jet polisher using a solution consisting of $10 \% \mathrm{HF}$, $60 \% \mathrm{H}_{2} \mathrm{O}_{2}$ and $30 \% \mathrm{H}_{2} \mathrm{O}$.

\section{Results and discussion}

\subsection{Vickers micro-hardness test analysis}

As for the metallic components, the increase of microhardness can restrain cracks initiation from the surface, which plays an important role in enhancing the fatigue performance [33]. Figure 5a shows the profiles of the micro-hardness distribution along the cross-sectional direction of the specimens before and after $\mathrm{LPwC}$ with three different laser impacts. The surface micro-hardness of the $\mathrm{AC}$ specimen is $402.8 \mathrm{HV}_{0.5}$; the LPwC-treated specimens with 1 impact exhibit an average surface hardness of $459.2 \mathrm{HV}_{0.5}$ and was increased by $14 \%$ from the $\mathrm{AC}$ specimen. With the increase of laser impacts, the surface micro-hardness is $482 \mathrm{HV}_{0.5}$ and $494.2 \mathrm{HV}_{0.5}$ for 3 impacts and 5 impacts, respectively. The surface microhardness of the target material increases with LPwC impacts, but the improvement magnitude is limited for more impacts. It shows that the hardness improvement of the titanium alloy tends to saturate with increasing the laser impacts. Similar results on TC6 titanium alloy were also found by Nie et al. [34]. They attributed this trend to the plastic deformation limit of material in the surface. In contrast to the present study, it was reported by A. Umapathi et al. [26] that the increase of the laser impacts did not induce the hardening but softening of the TC6 titanium alloy with multiple peening at $6 \mathrm{GW} / \mathrm{cm}^{2}$. This apparent contrast can be explained by the repetition rate, as they used the repetition rate of $10 \mathrm{~Hz}$ in comparison with the present study $(3 \mathrm{~Hz})$, because lower repetition rate can provide the sample with enough time to cool down. As a result, the thermal softening effects will be weakened or even eliminated, and finally the mechanical effects dominate the LPwC process.

Along the cross-sectional direction, it can be seen that the highest hardness of the target material is not on the surface but on the subsurface. Without the protective coating, the direct laser irradiation on the surface of specimen may induce the softening of the material on the surface [24, 35]. For all LPwC-treated samples, the maximum micro-hardness appears at the depth of $20 \mu \mathrm{m}$, which is a consequence of the softening due to the thermal effects on the sample surface and the similar results at the surface can be seen from the open literature [19, 26]. The hardness of all LPwCed titanium alloy samples decreases along the depth and finally reaches that of the AC specimen. The thermal effects are usually attributed to local melting and re-solidification on the sample surface. However, in the present study, no melting or re-solidification was observed, as evident from the microstructural cross-sectional
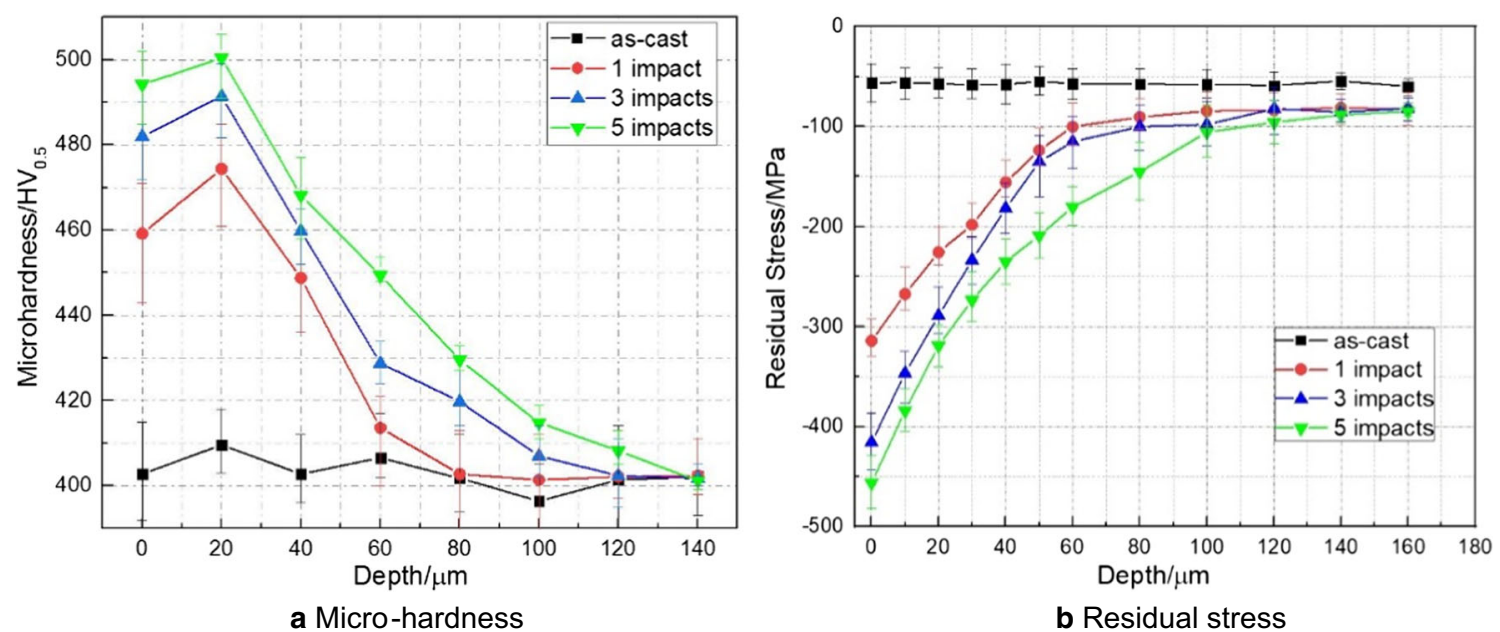

Fig. 5 Vickers micro-hardness and residual stress along the cross-sectional direction of titanium alloys under different LPwC impacts. a Micro-hardness. b Residual stress 
graphs presented in Section 3.3. It was suggested by A. Umapathi et al. [36] that the adiabatic heating also contributed to the thermal softening of the target material. In the present study, high-density dislocations generated after LPwC (in Fig. 8) could assist the frictional dissipation, which will increase the chance of adiabatic heating. Therefore, it can be concluded that the adiabatic heating caused the surface softening of the Ti-17 titanium alloy after LPwC.

The affected depth of hardness increases from $80 \mu \mathrm{m}$ for one LPwC impact to $140 \mu \mathrm{m}$ for five impacts. For most crystalline alloys, the micro-hardness enhancement is attributed to the laser-induced high-density dislocations in the crystals [13, 37] and also the compressive residual stress [38, 39] after peening. The effect of laser peening without coating on the residual stress distribution and microstructure evolution will be discussed in Sections 3.2 and 3.3.

\subsection{Residual stress distribution}

Some previous investigations $[15,17,20]$ reported that the thermal effect of $\mathrm{LPwC}$ with less than $0.5 \mathrm{~J}$ is very small or even negligible, and then the effect of shock waves under this condition is prevailing. Under the effect of the laser-induced shock wave, compressive residual stress was introduced in the surface and subsurface of the metal material. The depth-wise residual stress profiles with different numbers of laser impacts are depicted in Fig. 5b. The residual stress of the AC specimen is about $-50 \mathrm{MPa}$ compressive residual stress, which is so small that the effect of the initial residual stress on the high cycle fatigue strength can be neglected. It can be seen that compressive residual stress was generated on the surface of the Ti-17 titanium alloy, $-314.2,-415.5$ and $-456.1 \mathrm{MPa}$, after LPwC with one, three and five impacts, respectively. It can be demonstrated that the thermal effect of LPwC is negligible and $\mathrm{LPwC}$ can effectively induce the compressive residual stress. It is well known that the enhancement of the hardness is partially attributed to compressive residual stress. This
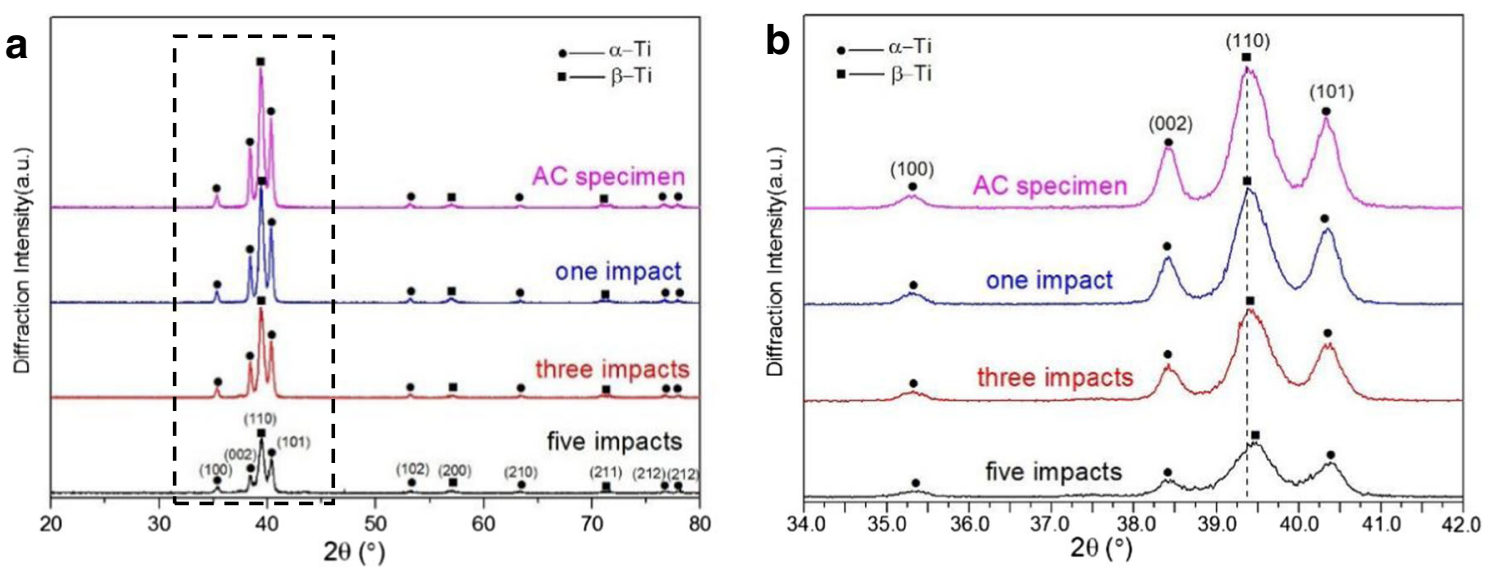

Fig. 6 a XRD patterns of Ti-17 titanium alloy with and without LPwC; $\mathbf{b}$ zoomed figure of $(\mathbf{a})$ in the range of $38-42^{\circ}$ is caused by the accumulated plastic strain induced by longer deformation time [40]. However, the increment of the surface residual compressive stress for each impact decreases with LPwC impact, which may be attributed to the plastic deformation limit of material on the surface. It consistents with the variation of the micro-hardness. This residual stress distribution observed in the present study can also be explained by that for the micro-hardness variation (Section 3.1).

The largest value of the compressive residual stress is on the surface of the specimen, and it goes on decreasing as it goes inward. This occurs due to the fact that the intensity of the laser-induced shock wave is the maximum on the surface and the kinetic energy of shock wave is absorbed by the plastic deformation. As a result, the compressive residual stress decreases along the in-depth direction. The affected depths of the specimen after LPwC were 100, 120 and $160 \mu \mathrm{m}$, after one, three and five impacts, respectively. Compared with the laser shock peening with large energy ( $>1 \mathrm{~J}$ ) [34], the affected depth is shallower, which can be attributed to the lower energy and shorter pulse duration time.

\subsection{Microstructure analysis}

Figure 6a is the XRD patterns of Ti-17 titanium alloy with and without LPwC and Fig. $6 \mathrm{~b}$ is the zoomed figure of (a) in the range of $38-42^{\circ}$. It can be seen from Fig. 6 that the AC specimen and LPwCed specimens predominantly consist of $\alpha$ phase and $\beta$ phase, which can verify the results in Fig. 2. In addition, there are no new peaks on the Ti-17 titanium alloy after LPwC, indicating that no phase changes generated, no new crystalline phase is formed and the specimens after LPwC still consists of $\alpha$-Ti and $\beta$-Ti dual phases. However, the diffraction peak location corresponding to $\beta$ phase in (110) crystalline plane shifts to higher angle (39.32 to $\left.39.44^{\circ}\right)$ and the full width at half maximum (FWHM) of the diffraction peak (110) was increased from 0.46 to $0.58^{\circ}$ when the laser impacts increase from 0 to 5 . In addition, with the increase of the laser impacts, the diffraction 
turns to be smooth and the diffraction peak intensity decreases. The broadened peak, the location movement and the decreased intensity may be attributed to increased dislocation density and the formation of refined microstructures on the surface layer of the LPwCed specimens [34, 41].

The cross-sectional microstructure of the Ti-17 titanium alloy specimens is shown in Fig. 7. Figure 7a presents the typical structure of the AC Ti-17 titanium alloy and Fig. 7b is the enlarged view of Fig. 7a. It is shown that Ti-17 titanium alloy consists of globular $\alpha$ phase and acicular $\beta$ phases, with a small amount of columnar $\alpha$ phase. Compared with the cross-sectional microstructures of the AC samples, there is no distinguished grain refinement in the surface layer of the LPwCed specimens. It can be seen from Fig. $7 \mathrm{c}$ and $\mathrm{d}$ that there is no melted layer in the subsurface of LPwCed specimen, which can demonstrate that the direct laser ablationinduced surface melting does not have any appreciable effect. The low laser energy and short pulse duration can lead to the thermodynamically non-equilibrium of the $\mathrm{LPwC}$ process which could be the reason for the low thermal effect under no protective coating condition [27]. In order to further explore the microstructural changes under $\mathrm{LPwC}$, higher resolution method (TEM observation) was conducted on the $\mathrm{AC}$ and LPwCed specimens.

TEM observations of Ti-17 titanium alloy with and without $\mathrm{LPwC}$ are shown in Fig. 8. Figure 8a and $\mathrm{b}$ indicate the original features of the Ti-17 titanium alloy specimens. It can be seen that the original Ti-17 titanium alloy is composed of $\alpha$ phase and $\beta$ phase with acicular structures, which is consistent with the XRD and SEM results. Figure 8c and d show the TEM images of the LPwCed sample. It is obvious that high-density dislocations were introduced on the surface of Ti-17 titanium alloy by the laser peening without coating compared with the microstructure of AC sample in Fig. 8a and b. As mentioned above, the acicular $\beta$ phase is the matrix phase and is distributed regularly. It can be seen from Fig. $8 \mathrm{c}$ and $\mathrm{d}$ that the highdensity dislocation arrangements are in acicular phase, which should be the $\beta$ phase. Thus, it can be concluded that the dislocation density in the $\beta$ phase was significantly increased after the LPwC. The formation of high-density dislocations may be ascribed to the laser-induced high-pressure shock wave. Under the effect of the laser-induced shock wave, dislocations start to move, and dislocations lines are generated [37]. With the further plastic deformation, dislocation slipping is generated along different slip planes, which results in the accumulation of dislocations. Eventually, the dislocation density increases, and it contributes to the improvement in hardness of the LPwCed Ti-17 titanium alloy. Therefore, the root cause of hardening of the material is the laser-induced shock wave.

\subsection{High cycle fatigue performance and fracture morphology}

\subsubsection{High cycle fatigue performance}

The as-cast plates were divided into three groups and each group has three specimens to ensure the statistical reliability, the first group is the as-cast, the second one is the $\mathrm{LPwC}$
Fig. 7 Cross-sectional SEM graph of Ti-17 titanium alloy with and without $\mathrm{LPwC}$ a $\mathrm{AC}$ specimen; $\mathbf{b}$ enlarged view of (a); c LPwCed sample with 1 impact; d enlarged view of (c)
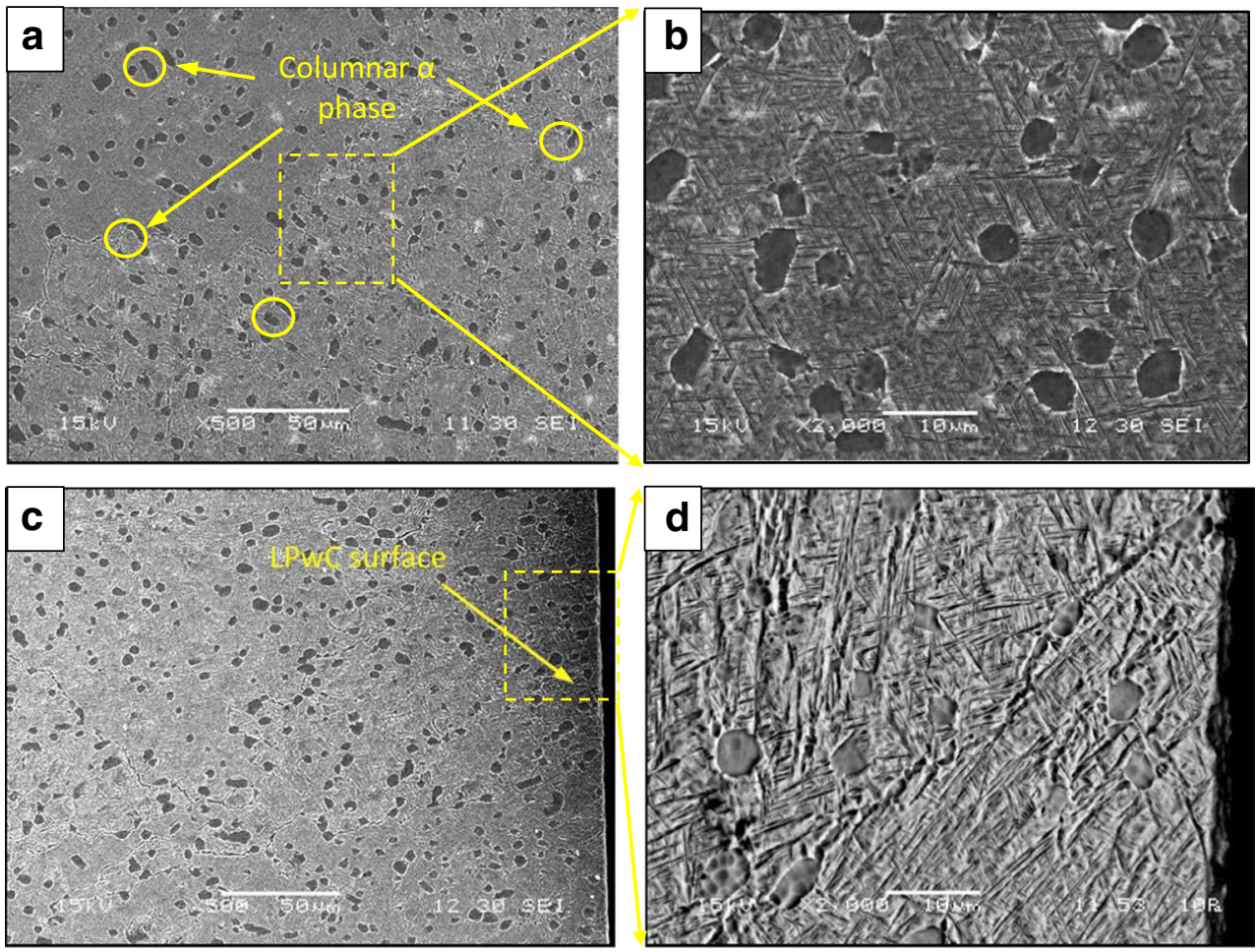
Fig. 8 TEM observation of Ti-17 titanium alloy. a, b Without LPwC. c, d LPwC with 3 laser impacts
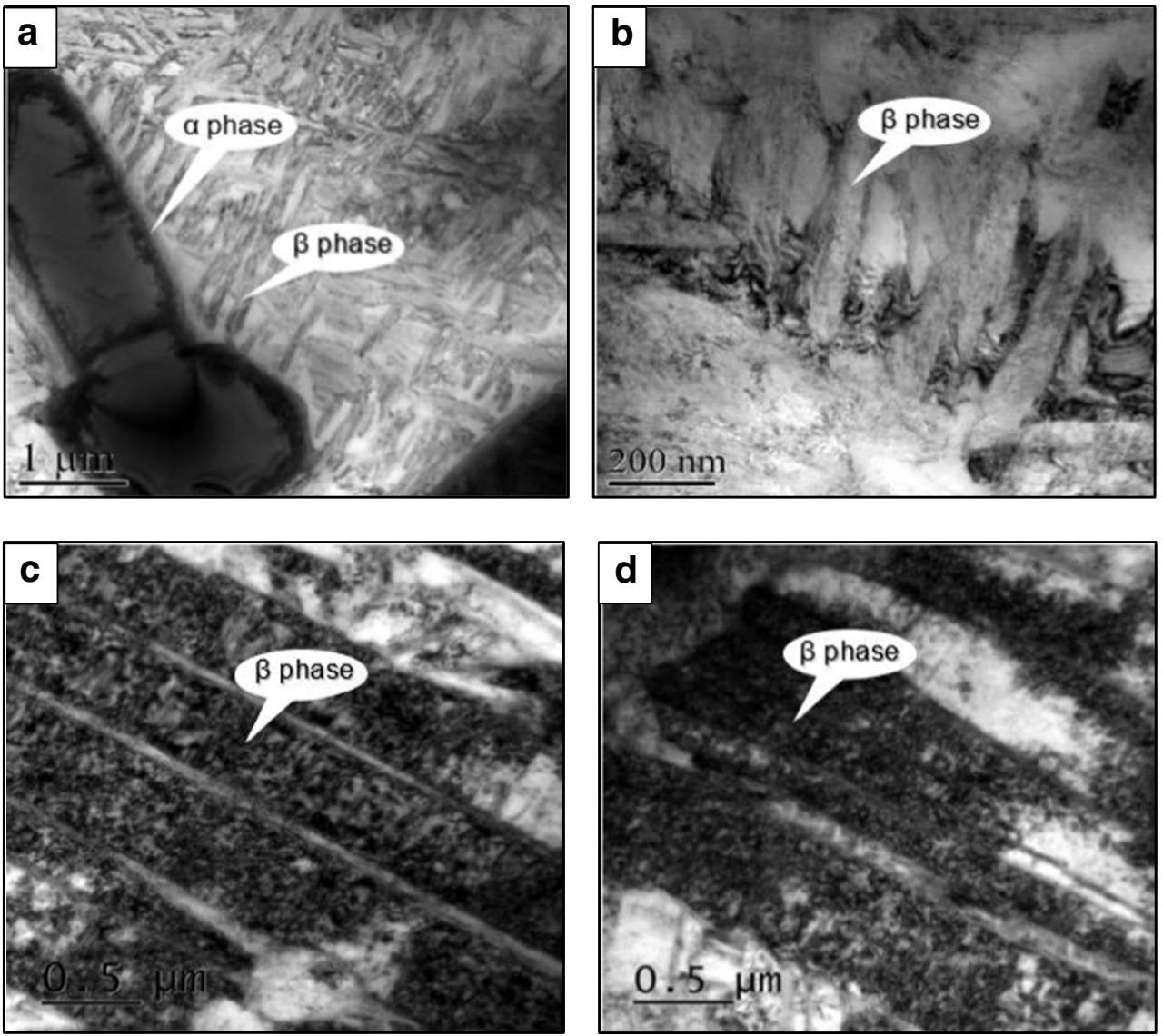

treated with one impact and the other one is the $\mathrm{LPwC}$ treated with three impacts. The laser treated path of all the fatigue specimens are as shown in Fig. 1. The high cycle fatigue behaviours of the Ti-17 titanium alloy with different surface conditions are shown in Table 3 and the data was collected with the step-loading method. Taking the mechanical properties of Ti-17 titanium alloys into consideration, the initial stress of the as-cast specimen was set to be $300 \mathrm{MPa}$ and the loading history of the specimens is shown in Fig. 9a. For the sake of avoiding the failure of the specimens, $300 \mathrm{MPa}$ was also set to be the initial stress of the LPwCed specimen but it came out that the fatigue strength is almost $480 \mathrm{MPa}$. Therefore, in order to save time, the initial stress of the LPwC specimens was then increased to $390 \mathrm{MPa}$. The average value of each group is taken as the fatigue strength of the specimens under the surface condition and the results are 360 $\mathrm{MPa}, 475.4 \mathrm{MPa}$ and $490.3 \mathrm{MPa}$, respectively, as shown in Fig. 9b. It can be clearly seen that laser peening without

Table 3 High cycle fatigue test results of titanium alloys with different surface conditions

\begin{tabular}{lllllll}
\hline Specimen & Surface condition & Initial stress $(\mathrm{MPa})$ & $\begin{array}{l}\text { Increment } \\
\Delta \sigma(\mathrm{MPa})\end{array}$ & $\begin{array}{l}\text { Failure stress } \\
\sigma_{1}(\mathrm{MPa})\end{array}$ & $\begin{array}{l}\text { Failure cycles } \\
N_{1}\end{array}$ & $\begin{array}{l}\text { Fatigue strength } \\
\sigma_{1}(\mathrm{MPa})\end{array}$ \\
\hline S-01 & As-cast & 300 & 30 & 390 & $7.21 \times 10^{5}$ & 381.7 \\
S-02 & As-cast & 300 & 30 & 330 & $3.50 \times 10^{5}$ & 310.5 \\
S-03 & As-cast & 300 & 30 & 390 & $9.33 \times 10^{5}$ & 387.9 \\
S-04 & 1 impact & 300 & 30 & 510 & $1.31 \times 10^{5}$ & 483.9 \\
S-05 & 1 impact & 390 & 30 & 450 & $8.32 \times 10^{5}$ & 444.9 \\
S-06 & 1 impact & 390 & 30 & 510 & $5.81 \times 10^{5}$ & 497.4 \\
S-07 & 3 impacts & 390 & 30 & 510 & $1.63 \times 10^{5}$ & 484.9 \\
S-08 & 3 impacts & 390 & 30 & 510 & $7.20 \times 10^{5}$ & 483.6 \\
S-09 & 3 impacts & 390 & 510 & $7.50 \times 10^{5}$ & 502.5 \\
\hline
\end{tabular}



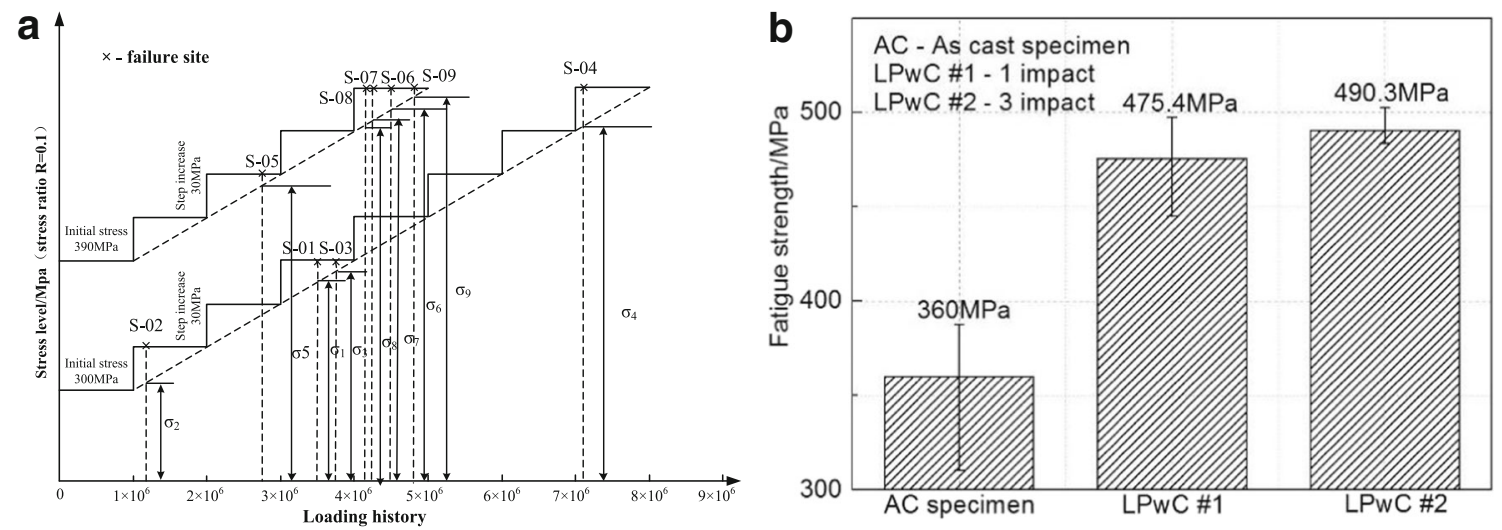

Fig. 9 Loading history (a) and fatigue strength (b) of the Ti-17 titanium alloy specimens with different laser parameters

coating can improve the high cycle fatigue performance of Ti17 titanium alloy significantly and the improvement of 3 laser impacts $(36.16 \%)$ is higher than that of 1 laser impact (31.96\%). However, compared with the fatigue strength improvement from as-cast to $\mathrm{LPwC}$ no. 1 specimen, the improvement from $\mathrm{LPwC}$ no. 1 specimen to $\mathrm{LPwC}$ no. 2 specimen is relatively small, which shows the similar trend with the compressive residual stress improvement and microhardness enhancement.

\subsubsection{Fracture morphology analysis}

In order to gain more insights into the effects of $\mathrm{LPwC}$ on the high cycle fatigue properties, the specimens with different surface conditions after fatigue test was observed by SEM as shown in Fig. 10. According to the fracture surface, the quasicleavage fracture with the typical features of river patterns was found on all the specimens. It can be seen that the fatigue crack initiation of the AC specimen appears on the surface
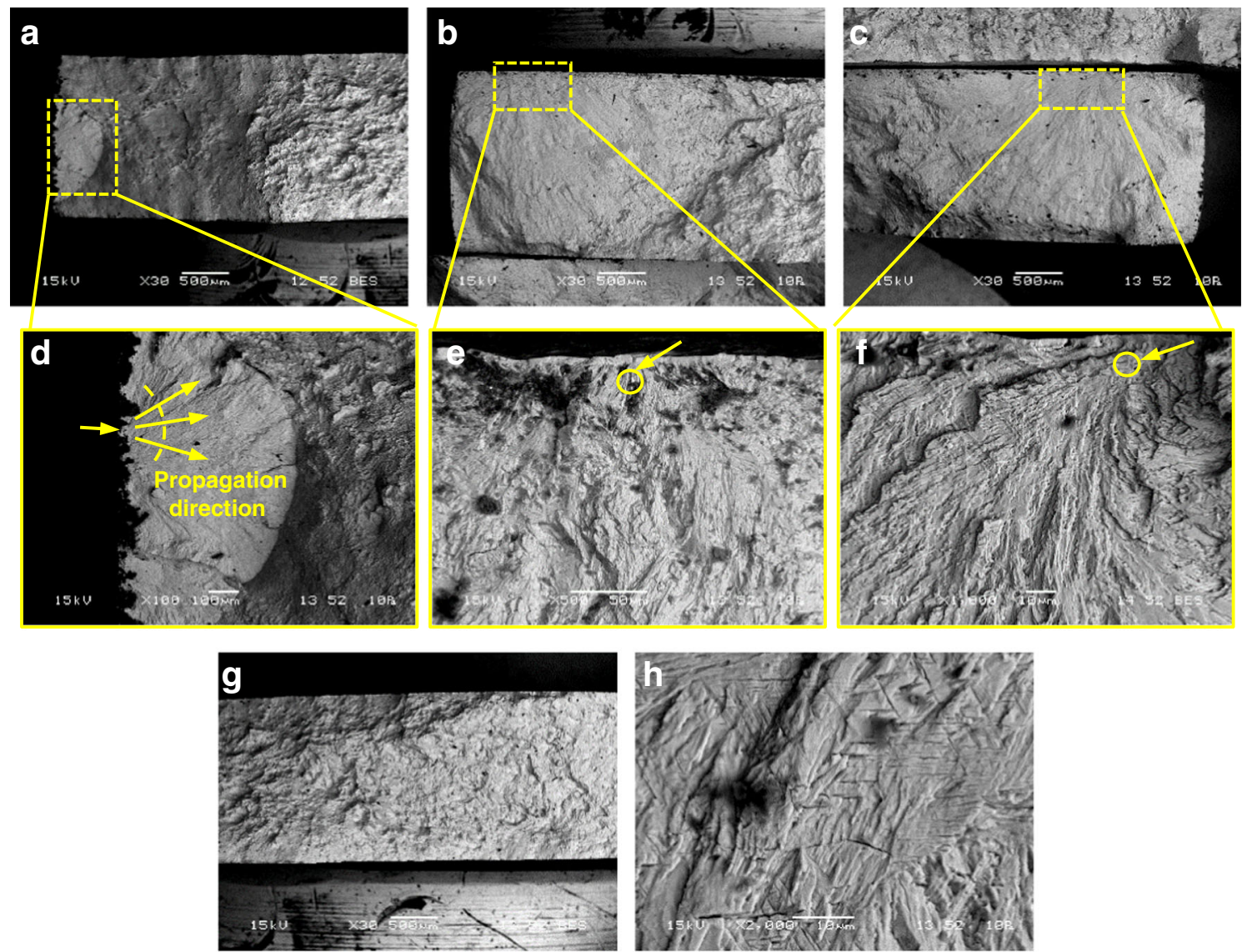

Fig. 10 Fracture morphology of specimens after fatigue test. a AC specimen, $\mathbf{b}$ LPwC no. 1, $\mathbf{c}$ LPwC no. 2 and panels $\mathbf{d}-\mathbf{f}$ were their corresponding enlarged views. $\mathbf{g}$ The final region of the AC specimen. $\mathbf{h}$ The final region of the $\mathrm{LPwC}$ no. 1 
(Fig. 10a), but the fatigue crack initiation of the LPwCed specimen is located in the subsurface, about several micrometres away from the surface (Fig. 10b, c), which can be attributed to the LPwC-induced compressive residual stress. In addition, there are some secondary fatigue cracks on the LPwCed specimens. Maxwell et al. [32] indicated that the secondary fatigue cracks can retard the propagation of the fatigue cracks. As is shown in Fig. $10 \mathrm{~g}$, some dimples can be found in the final fracture morphologies of the AC specimen. In Fig. 10h, a plenty of fatigue stripes were generated after LPwC, which may result from the combined effect of residual stress and high-density dislocations [42].

\subsection{Discussion}

Based on the residual stress distribution, micro-hardness test and microstructural characterisations, it is likely that the improvements of the high cycle fatigue performance on Ti-17 titanium alloy after LPwC are a consequence of the combined effects (1) according to the Goodman theory [43], the LPwCinduced high amplitude residual stress in the near-surface layer can reduce the effective working stress on the specimen, so the initiation of fatigue cracks in the surface layer is prevented. In addition, the compressive residual stress significantly increases the closing force of microscopic cracks and retards crack propagation via blocking and swerving. (2) Z. Zhang and D.L. Chen [44] proposed a prediction model that correlates the yield strength with the grain size and dislocation density, as described in the following equation:

$\sigma=\sigma_{0}+k d^{-1 / 2}+\alpha G b \rho^{1 / 2}$

where $\sigma$ is the strength, $\sigma_{0}$ is a friction stress, $k$ is the HallPetch constant, $d$ is the grain size, $\alpha$ is a constant, $G$ is the shear modulus, $b$ is the Burgers vector and $\rho$ is the dislocation density. It can be seen that the grain refinement and the dislocation density increase can lead to the enhancement of the strength. According to the SEM and TEM results in the present study, LPwC can introduce high-density dislocations on the surface layer but no distinct effects on the grain size. Therefore, the high-density dislocations play an important role in the enhancement of high cycle fatigue performance from the microstructural perspective. Since the high-density dislocations can restrain the slip deformation and plastic flow for crack growth. Hence, the strength of the LPwCed specimens is higher than that of the $\mathrm{AC}$ specimens.

\section{Conclusions}

In this paper, the effects of multiple laser peening without coating (LPwC) on the residual stress and micro-hardness distribution, microstructural evolution and high cycle fatigue strength of Ti-17 titanium alloy were investigated. The high cycle fatigue strengthening mechanism of the Ti-17 titanium alloy with LPwC treatment was revealed from microstructural change and mechanical property improvement. The fatigue test results show that LPwC can effectively improve the high cycle fatigue strength from 390 to $475.4 \mathrm{MPa}$ (1 impact) and then $490.3 \mathrm{MPa}$ (3 impacts). High amplitude compressive residual stress $(-456.1 \mathrm{MPa})$ was introduced on the surface of the Ti-17 titanium alloy after LPwC treatment with 5 impacts. The microstructural characterization results show that only high-density dislocations were generated on the LPwCed surface layer and no grain refinement can be found there. Therefore, the enhancement of high cycle fatigue strength was attributed to the combined effects of LPwC-induced compressive residual stress and high-density dislocations.

Funding information This work was supported by the National Key Research and Development Program of China (2016YFB1102600) and National Fundamental Research Program of China (No. 2015CB057400).

Open Access This article is distributed under the terms of the Creative Commons Attribution 4.0 International License (http:// creativecommons.org/licenses/by/4.0/), which permits unrestricted use, distribution, and reproduction in any medium, provided you give appropriate credit to the original author(s) and the source, provide a link to the Creative Commons license, and indicate if changes were made.

\section{References}

1. Ezugwu EO, Bonney J, Yamane Y (2003) An overview of the machinability of aeroengine alloys. J Mater Process Technol 134: 233-253

2. Leyens C, Peters M (2001) Titanium and titanium alloys: fundamentals and applications. Cologne, Germany

3. Boyer RR (1996) An overview on the use of titanium in the aerospace industry. Mater Sci Eng A 213:103-114

4. Crall D, Linko P, English C, Busbey B (1998) Laser twist weld repair of compressor blisk airfoils. 34th AIAA/ASME/SAE/ASEE Joint Propulsion Conference and Exhibit, Joint Propulsion Conferences, Cleveland

5. Cellard C, Retraint D, Francois M, Rouhaud E, Saunier D (2012) Laser shock peening of Ti17 titanium alloy influence of process parameters. Mater Sci Eng A 532:362-372

6. Spanrad S, Tong J (2010) Characterisation of foreign object damage (FOD) and early fatigue crack growth in laser shock peened Ti-6Al4V aerofoil specimens. Procedia Eng 2:1751-1759

7. Tanaka S, Kawahara T, Okada H (2014) Study on crack propagation simulation of surface crack in welded joint structure. Mar Struct 39:315-334

8. Sangid MD (2013) The physics of fatigue crack initiation. Int $\mathbf{J}$ Fatigue 57:58-72

9. Thomas M, Jackson M (2012) The role of temperature and alloy chemistry on subsurface deformation mechanisms during shot peening of titanium alloys. Scr Mater 66:1065-1068

10. Li H, Liu Y, Li M, Liu H (2015) The gradient crystalline structure and microhardness in the treated layer of TC17 via high energy shot peening. Appl Surf Sci 357:197-203 
11. Wen M, Liu G, Gu JF, Guan WM, Lu J (2008) The tensile properties of titanium processed by surface mechanical attrition treatment. Surf Coat Technol 202:4728-4733

12. Wu JF, Zou SK, Zhang YK et al (2017) Microstructures and mechanical properties of $\beta$ forging Ti17 alloy under combined laser shock processing and shot peening. Surf Coat Technol 328:283291

13. Mukai N, Aoki N, Obata M, Ito A, Sano Y, Konagai C (1995) Proceedings of the Third JSME/ASME International Conference on Nuclear Engineering (ICONE-3), Kyoto, pp 1489-1494

14. Sano Y, Mukai N, Okazaki K, Obata M (1997) Residual stress improvement in metal surface by underwater laser irradiation. Nucl Instrum Methods Phys Res, Sect B 121:432-436

15. Sano YJ, Obata M, Kubo T, Mukai N, Yoda M, Masaki K, Ochi Y (2006) Retardation of crack initiation and growth in austenitic stainless steels by laser peening without protective coating. Mater Sci Eng A 417:334-340

16. Karthik D, Swaroop S (2016) Laser peening without coating induced phase transformation and thermal relaxation of residual stresses in AISI 321 steel. Surf Coat Technol 291:161-171

17. Kalainathan S, Sathyajith S, Swaroop S (2012) Effect of laser shot peening without coating on the surface properties and corrosion behavior of 316 L steel. Opt Lasers Eng 50:1740-1745

18. Karthik D, Kalainathan S, Swaroop S (2015) Surface modification of $17-4 \mathrm{pH}$ stainless steel by laser peening without protective coating process. Surf Coat Technol 278:138-145

19. Prabhakaran S, Kulkarni A, Vasanth G, Kalainathan S, Shukla P, Vasudevan VK (2018) Laser shock peening without coating induced residual stress distribution, wettability characteristics and enhanced pitting corrosion resistance of austenitic stainless steel. Appl Surf Sci 428:17-30

20. Sano Y, Masaki K, Gushi T, Sano T (2012) Improvement in fatigue performance of friction stir welded A6061-T6 aluminum alloy by laser peening without coating. Mater Des 36:809-814

21. Ochi Y, Matsumura T, Ikarashi T, Masaki K, Kakiuchi T, Sano Y, Adachi T (2010) Effects of laser peening treatment without protective coating on axial fatigue property of aluminium alloy. Procedia Eng 2:491-498

22. Correa C, Peral D, Porro JA, Díaz M, Ruiz de Lara L, GarcíaBeltrán A, Ocaña JL (2015) Random-type scanning patterns in laser shock peening without absorbing coating in 2024-T351 Al alloy: a solution to reduce residual stress anisotropy. Opt Laser Technol 73: 179-187

23. Trdan U, Porro JA, Ocaña JL, Grum J (2012) Laser shock peening without absorbent coating (LSPwC) effect on 3D surface topography and mechanical properties of 6082-T651 Al alloy. Surf Coat Technol 208:109-116

24. Sathyajith S, Kalainathan S, Swaroop S (2013) Laser peening without coating on aluminum alloy Al-6061-T6 using low energy Nd: YAG laser. Opt Laser Technol 45:389-394

25. Umapathi A, Swaroop S (2016) Residual stress distribution in a laser peened Ti-25Cu alloy. Surf Coat Technol 307:38-46

26. Umapathi A, Swaroop S (2018) Deformation of single and multiple laser peened TC6 titanium alloy. Opt Laser Technol 100:309-316

27. Maawad E, Sano Y, Wagner L, Brokmeier HG, Genzel C (2012) Investigation of laser shock peening effects on residual stress state and fatigue performance of titanium alloys. Mater Sci Eng A 536: $82-91$

28. Altenberger I, Nalla RK, Sano Y, Wagner L, Ritchie RO (2012) On the effect of deep-rolling and laser-peening on the stress-controlled low- and high-cycle fatigue behavior of Ti-6Al-4V at elevated temperatures up to $550^{\circ} \mathrm{C}$. Int J Fatigue 44:292-302

29. Berthe L, Fabbro R, Peyre P, Bartnicki E (1998) Experimental study of the transmission of breakdown plasma generated during laser shock processing. Eur Phys J Appl Phys 3:215-218

30. Zhou JZ, Meng XK, Huang S, Sheng J, Lu JZ, Yang ZR, Su C (2015) Effects of warm laser peening at elevated temperature on the low-cycle fatigue behavior of Ti6A14V alloy. Mater Sci Eng A 643: 86-95

31. Nicholas T (2002) Step loading for very high cycle fatigue. Fatigue Fract Eng Mater Struct 25:861-869

32. Maxwell DC, Nicholas T (1999) A rapid method for generation of a haigh diagram for high cycle fatigue. In: Panontin TL, Sheppard SD (eds) Fatigue and Fracture Mechanics: 29th volume, ASTM STP 1321. American Society for Testing and Materials, West Conshohocken, pp 626-641

33. Li J, Zhou JZ, Feng AX et al (2018) Investigation on mechanical properties and microstructural evolution of TC6 titanium alloy subjected to laser peening at cryogenic temperature. Mater Sci Eng A 734:291-298

34. Nie XF, He WF, Zhou LC, Li Q, Wang XD (2014) Experiment investigation of laser shock peening on TC6 titanium alloy to improve high cycle fatigue performance. Mater Sci Eng A 594:161167

35. Prabhakaran S, Kalainathan S (2016) Compound technology of manufacturing and multiple laser peening on microstructure and fatigue life of dual-phase spring steel. Mater Sci Eng A 674:634645

36. Umapathi A, Swaroop S (2017) Wavelength dependent deformation in a laser peened Ti-2.5Cu alloy. Mater Sci Eng A 684:344-352

37. Lu JZ, Luo KY, Zhang YK, Sun GF, Gu YY, Zhou JZ, Ren XD, Zhang XC, Zhang LF, Chen KM, Cui CY, Jiang YF, Feng AX, Zhang L (2010) Grain refinement mechanism of multiple laser shock processing impacts on 304 stainless steel. Acta Mater 58: 5354-5362

38. Chen X, Yan J, Karlsson AM (2006) On the determination of residual stress and mechanical properties by indentation. Mater Sci Eng A 416:139-149

39. Carlsson S, Larsson PL (2001) On the determination of residual stress and strain fields by sharp indentation testing. Part I: theoretical and numberical analysis. Acta Mater 49:2179-2191

40. Chahardehi A, Brennan FP, Steuwer A (2010) The effect of residual stresses arising from LSP on fatigue crack growth. Eng Fract Mech 77:2033-2039

41. Gu DD, Hagedorn YC, Meiners W, Meng GB, Batista RJS, Wissenbach K, Poprawe R (2012) Densification behavior, microstructure evolution, and wear performance of selective laser melting processed commercially pure titanium. Acta Mater 60:3849-3860

42. Qiao HC (2015) Experimental investigation of laser peening on Ti17 titanium alloy for rotor blade applications. Appl Surf Sci 351:524-530

43. Ei Haddad MH, Topper KJ, Pook LP (1974) Metal fatigue. Oxford University Press, London

44. Zhang Z, Chen DL (2006) Consideration of Orowan strengthening effect in particulate-reinforced metal matrix nanocomposites: a model for predicting their yield strength. Scr Mater 54:1321-1326

Publisher's note Springer Nature remains neutral with regard to jurisdictional claims in published maps and institutional affiliations. 